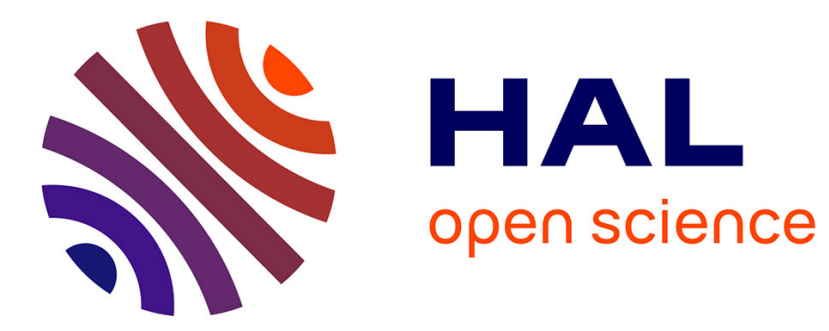

\title{
Tracer diffusion of $\mathrm{Cr}$ in $\mathrm{Ni}$ and $\mathrm{Ni}-22 \mathrm{Cr}$ studied by SIMS
}

Thomas Gheno, François Jomard, Clara Desgranges, Laure Martinelli

\section{To cite this version:}

Thomas Gheno, François Jomard, Clara Desgranges, Laure Martinelli. Tracer diffusion of $\mathrm{Cr}$ in $\mathrm{Ni}$ and Ni-22Cr studied by SIMS. Materialia, 2018, 3, pp.145-152. 10.1016/j.mtla.2018.08.004 . hal02350036

\section{HAL Id: hal-02350036 \\ https://hal.science/hal-02350036}

Submitted on 5 Nov 2019

HAL is a multi-disciplinary open access archive for the deposit and dissemination of scientific research documents, whether they are published or not. The documents may come from teaching and research institutions in France or abroad, or from public or private research centers.
L'archive ouverte pluridisciplinaire HAL, est destinée au dépôt et à la diffusion de documents scientifiques de niveau recherche, publiés ou non, émanant des établissements d'enseignement et de recherche français ou étrangers, des laboratoires publics ou privés.

\section{(ㅇ)(1) $\$$}

Distributed under a Creative Commons Attribution - NonCommercial - NoDerivatives| 4.0 


\title{
Tracer diffusion of $\mathrm{Cr}$ in $\mathrm{Ni}$ and $\mathrm{Ni}-22 \mathrm{Cr}$ studied by SIMS
}

\author{
Thomas Gheno $^{\mathrm{a} *}(\mathbb{D})$, François Jomard ${ }^{\mathrm{b}}$, Clara Desgranges ${ }^{\mathrm{a}, \mathrm{c}}(\mathbb{D})$ and \\ Laure Martinelli ${ }^{\mathrm{a}}$ (D) \\ ${ }^{a}$ DEN-SCCME, CEA, Université Paris-Saclay, 91191 Gif-sur-Yvette, France \\ ${ }^{b}$ GEMaC, UMR 8635, Université de Versailles-Saint-Quentin, \\ 45 avenue des Etats-Unis, 78035 Versailles, France \\ ${ }^{c}$ Safran-Tech, rue des jeunes bois, Châteaufort, 78772 Magny-les-Hameaux, France
}

This is the accepted version of an article published in Materialia, available at: https://doi.org/10.1016/j.mtla.2018.08.004

This version is made available under the CC-BY-NC-ND 4.0 license

\begin{abstract}
The volume diffusion of $\mathrm{Cr}$ in $\mathrm{Ni}$ and in $\mathrm{Ni}-22 \mathrm{Cr}$ (at. \%) was studied from tracer experiments, using ${ }^{52} \mathrm{Cr}$ and ${ }^{54} \mathrm{Cr}$ as tracers, in the temperature range $542-843{ }^{\circ} \mathrm{C}$. Intensity-depth profiles were generated by secondary ion mass spectrometry (SIMS), which allowed data to be obtained at substantially lower temperatures than previously available. Chromium diffusion was found to be slightly slower in $\mathrm{Ni}-22 \mathrm{Cr}$ than in $\mathrm{Ni}$, in agreement with literature data at high temperature. The mobility parameters $\left(\ln \left(D_{0}\right)_{\mathrm{Cr}}^{\mathrm{Ni}}=-1.6 \pm 0.3\left[\mathrm{~cm}^{2} / \mathrm{s}\right]\right.$, $Q_{\mathrm{Cr}}^{\mathrm{Ni}}=260 \pm 2 \mathrm{~kJ} / \mathrm{mol}$ for $\mathrm{Cr}$ in $\mathrm{Ni}$, and $\ln \left(D_{0}\right)_{\mathrm{Cr}}^{\mathrm{Ni}-22 \mathrm{Cr}}=-0.3 \pm 1.3\left[\mathrm{~cm}^{2} / \mathrm{s}\right]$, $Q_{\mathrm{Cr}}^{\mathrm{Ni}-22 \mathrm{Cr}}=279 \pm 10 \mathrm{~kJ} / \mathrm{mol}$ for $\mathrm{Cr}$ in $\mathrm{Ni}-22 \mathrm{Cr}$ ) are in the lower range of those obtained by previous investigators in similar alloys. The present results indicate that the vacancy-solute exchange mechanism in effect at high temperature does not change significantly at least down to $542{ }^{\circ} \mathrm{C}$.
\end{abstract}

Keywords: Bulk diffusion; Atomic mobility; Vacancies; Tracer diffusion coefficient

\section{Introduction}

Metal alloys and coatings exposed to heat are subject to composition variations and phase transformations resulting from interactions with the service environment, e.g., thermo-mechanical ageing or high temperature corrosion. Anticipating microstructure transformations is key to evaluating property evolutions, and the lifetime to be expected given operational constraints. These issues can be addressed by thermodynamic and kinetic modeling: the Calphad method [1,2], in particular, can be expanded to simulate diffusion-induced processes via its coupling with a finite difference resolution of the diffusion equation [3-5]. The simulation relies on interdiffusion coefficients, which combine tracer diffusion coefficients with thermodynamic interactions arising from chemical potential gradients. Atomistic simulation methods also make use of tracer diffusion data to evaluate migration energies (see examples in atomistic kinetic Monte Carlo [6] and self-consistent mean field kinetic theory [7]).

The success of these strategies relies on the availability of experimental data and their critical assessment to produce appropriate databases. Diffusion coefficients in structural alloys are typically known at high temperatures, from $800-1000{ }^{\circ} \mathrm{C}$ to melting, which does not always overlap service temperatures. In applications

${ }^{*}$ Corresponding author. E-mail address: thomas.gheno@onera.fr 
requiring good mechanical and oxidation resistance, austenitic stainless steels are used up to $700{ }^{\circ} \mathrm{C}$, and nickel or cobalt alloys hardly above $1100{ }^{\circ} \mathrm{C}$. In nuclear power plants, alloys used in reactor internals are exposed to moderate temperatures of $300-350{ }^{\circ} \mathrm{C}$, but they may be in use without replacement for decades. Simulating industrially relevant processes can thus involve data extrapolation over large temperature ranges; this bears potential for significant errors, and prompts the need to complete the existing databases.

Chromium is included in austenitic steels and Ni-base alloys to provide protection against corrosion in a variety of applications. The existing experimental data for tracer diffusion of $\mathrm{Cr}$ in $\mathrm{Ni}$ and $\mathrm{NiCr}$ alloys are reviewed in Section 2. It appears that most results were obtained for temperatures above $950{ }^{\circ} \mathrm{C}$. Lower temperature data are needed if diffusion simulations are to be used for many industrial purposes.

The methods used by most investigators to measure tracer diffusivity involve machining (sectioning or grinding) to generate a depth-concentration profile. The depth resolution is then limited to about $0.1 \mu \mathrm{m}$ at best. To obtain a reliable profile, the diffusion distance should be at least a micrometer, which limits the range of temperatures where data can be obtained in a reasonable time. Ion sputtering in a modern SIMS instrument, on the other hand, provides a depth resolution in the nanometer range, which gives access to shorter diffusion distances, and lower temperatures. In impurity diffusion studies, or when stable isotopes of naturally low abundance can be procured, the high sensitivity of SIMS eliminates the need for radioactive tracers - for a discussion of SIMS use in tracer studies, the reader is referred to Ref. [8].

The present paper reports a study of volume diffusion of ${ }^{52} \mathrm{Cr}$ in $\mathrm{Ni}$ and ${ }^{54} \mathrm{Cr}$ in $\mathrm{Ni}-22 \mathrm{Cr}$ in the temperature range $542-843^{\circ} \mathrm{C}$, measured by SIMS. The primary aim was to extend the range of known diffusivity to as low a temperature as possible. The effect of substrate $\mathrm{Cr}$ concentration in the low temperature range was also examined.

\section{Survey of literature data}

Diffusivity in Ni-Cr fcc solid solutions was assessed by Jönsson [9] via the Calphad method. The tracer data for Cr diffusion in pure Ni [10-13] are shown in Fig. 1(a). The graph also includes interdiffusion coefficients determined at the terminal composition ( $0 \% \mathrm{Cr}$ ) from diffusion couple experiments in $\mathrm{NiCr}$ [14], and low temperature tracer data obtained recently by SIMS [15]. The data sets by Monma et al. [11], Růžičková and Million [13] and Jung et al. [14] are seen to follow a common trend; the other data sets are at variance with this trend, and are therefore considered doubtful. Overall, the lowest temperature at which reliable data are available is $950{ }^{\circ} \mathrm{C}$.

Each data set apparently follows an Arrhenius-type temperature dependence:

$$
D^{*}=D_{0} \exp \left(-\frac{Q}{R T}\right)
$$

where $D^{*}$ is the tracer coefficient, $D_{0}$ is the pre-exponential factor, $Q$ the activation energy, $R$ the ideal gas constant and $T$ the temperature. Values of $\ln \left(D_{0}\right)$ and $Q$ are reported in Table 1. The values reported by Růžičková and Million were presumably 


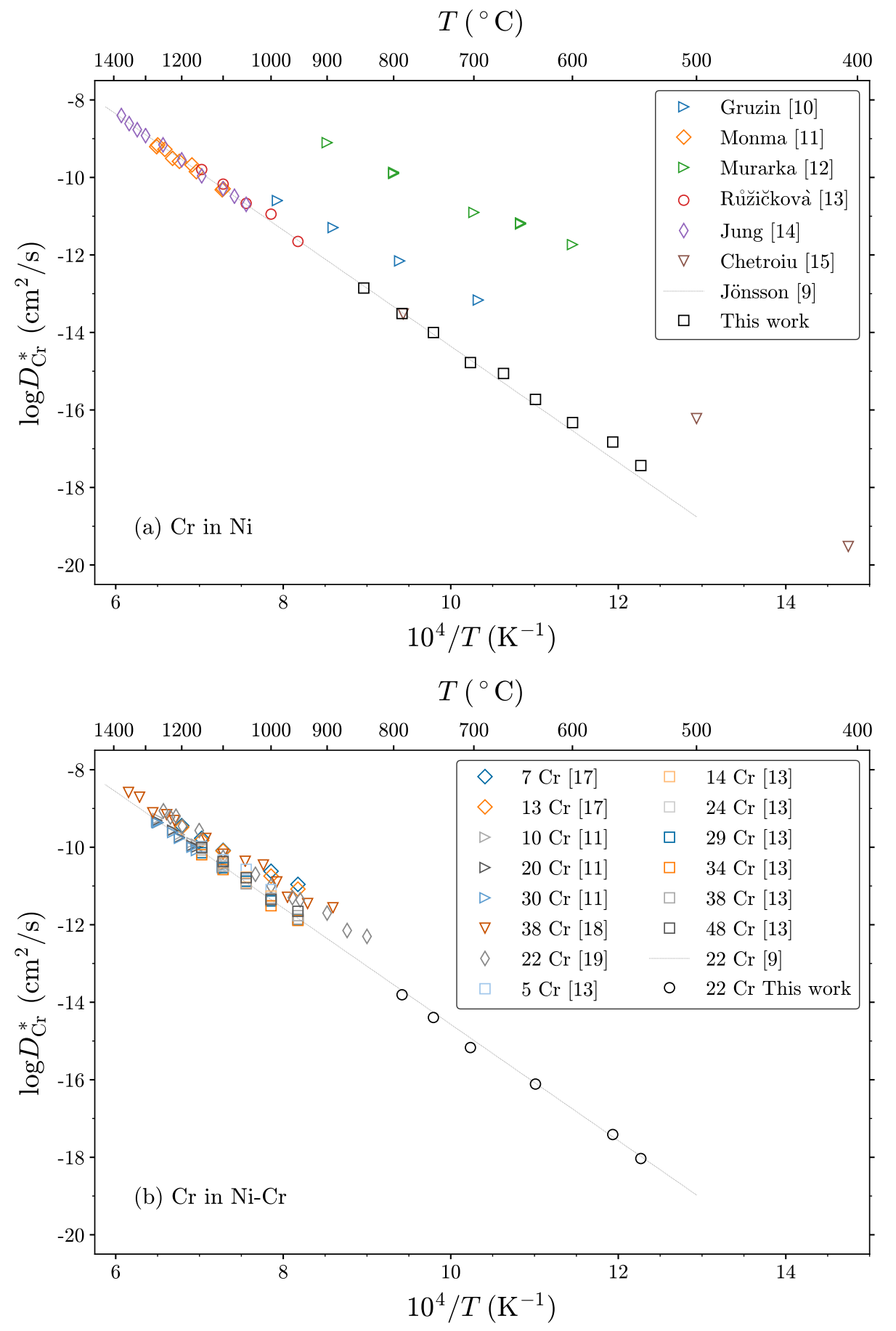

Figure 1: Tracer diffusion data from the literature: (a) $\mathrm{Cr}$ in $\mathrm{Ni}$; (b) $\mathrm{Cr}$ in NiCr alloys (concentrations in at. \%). Dotted lines drawn from Jönsson's assessment [9] (with $x_{\mathrm{Cr}}=0$ in (a) and $x_{\mathrm{Cr}}=0.22$ in (b)). Present results added for comparison. 
Table 1: Diffusivity parameters for Cr diffusion in Ni from literature data. All values were re-evaluated here from a linear fit of Eq. (2) to the original diffusion data.

\begin{tabular}{lcccc}
\hline Reference & $\ln \left(D_{0}\right)\left[\mathrm{cm}^{2} / \mathrm{s}\right]$ & $\mathrm{Q}(\mathrm{kJ} / \mathrm{mol})$ & $\mathrm{T}\left({ }^{\circ} \mathrm{C}\right)$ & Experiment type \\
\hline Gruzin [10] & -4.8 & 205 & $695-988$ & ${ }^{51} \mathrm{Cr} /$ residual activity \\
Monma [11] & $8.8 \times 10^{-2}$ & 272 & $1100-1268$ & ${ }^{51} \mathrm{Cr} /$ serial sectioning \\
Murarka [12] & -3.6 & 171 & $600-900$ & ${ }^{51} \mathrm{Cr} /$ residual activity \\
Růžičková [13] & 2.8 & 300 & $950-1150$ & ${ }^{51} \mathrm{Cr} /$ residual activity \\
Jung [14] & 1.7 & 290 & $1050-1375$ & Interdiff. in NiCr/EPMA \\
Chetroiu [15] & -7.0 & 207 & $405-787$ & ${ }^{52} \mathrm{Cr} / \mathrm{SIMS}$ \\
\hline
\end{tabular}

obtained from a non-linear fit of Eq. (1). In order to compare the data sets on a consistent basis, all $\ln \left(D_{0}\right)$ and $Q$ were re-evaluated here from a fit of the linearized form of Eq. (1),

$$
\ln \left(D^{*}\right)=\ln \left(D_{0}\right)-\frac{Q}{R T},
$$

following the method used in the present work. The activation energy obtained for Jung et al.'s data, $290 \mathrm{~kJ} / \mathrm{mol}$, is close to that of Růžičková and Million's data $(300 \mathrm{~kJ} / \mathrm{mol})$; both are somewhat higher than that reported by Monma et al. $(272 \mathrm{~kJ} / \mathrm{mol})$. The difference is to be compared with the dispersion typical for this type of data. Self-diffusion of Ni provides a useful basis for comparison, as numerous data sets are available, and $Q_{\mathrm{Ni}}^{\mathrm{Ni}}$ is the same magnitude as $Q_{\mathrm{Cr}}^{\mathrm{Ni}}$. Campbell and Rukhin [16] conducted a statistical analysis of multiple-laboratory Ni self-diffusion data, and found standard deviations of $10-20 \mathrm{~kJ} / \mathrm{mol}$, depending on the estimation method.

Tracer data for $\mathrm{Cr}$ in binary $\mathrm{Ni}-\mathrm{Cr}$ alloys are relatively abundant; selected data sets $[11,13,17-19]$ are shown in Fig. 1(b). However, few studies include multiple compositions, and assessing the effect of composition on diffusivity is made difficult by the dispersion between laboratories. The data by Monma et al. [11] and Růžičková and Million [13] are plotted in Fig. 2, along with curves calculated from Jönsson's assessment [9]. Structural alloys typically contain up to 25 at. \% Cr. From Fig. 2, it appears that Cr diffusion in such alloys would be slightly slower than it is in pure Ni. The composition dependence of the pre-exponential factor and of the activation energy are not that clear, however. Values from various data sets are reported in Fig. 3. Both $D_{0}$ and $Q$ have a positive dependence on $x_{\mathrm{Cr}}$ when evaluated from Monma et al.'s data, but a negative dependence according to Růžičková and Million's data; the rest of the data is too scattered to help establish a trend. In any case, measurements are lacking for temperatures below about $950{ }^{\circ} \mathrm{C}$.

\section{$3 \quad$ Experimental procedures}

\subsection{Materials}

Tracer diffusion experiments were carried out using Ni (5N purity, from Goodfellow, France) and Ni-22 at. \% Cr (ICP analysis: 19.9 wt. \% Cr, main impurities (ppmw) $497 \mathrm{~V}, 385 \mathrm{Fe}, 110 \mathrm{Cu}, 40 \mathrm{Ti}, 31 \mathrm{Co}$, from Neyco, France) substrates, both provided as $1 \mathrm{~mm}$ plates in as-rolled condition. The plates were cut into $9 \times 9 \mathrm{~mm}$ coupons 

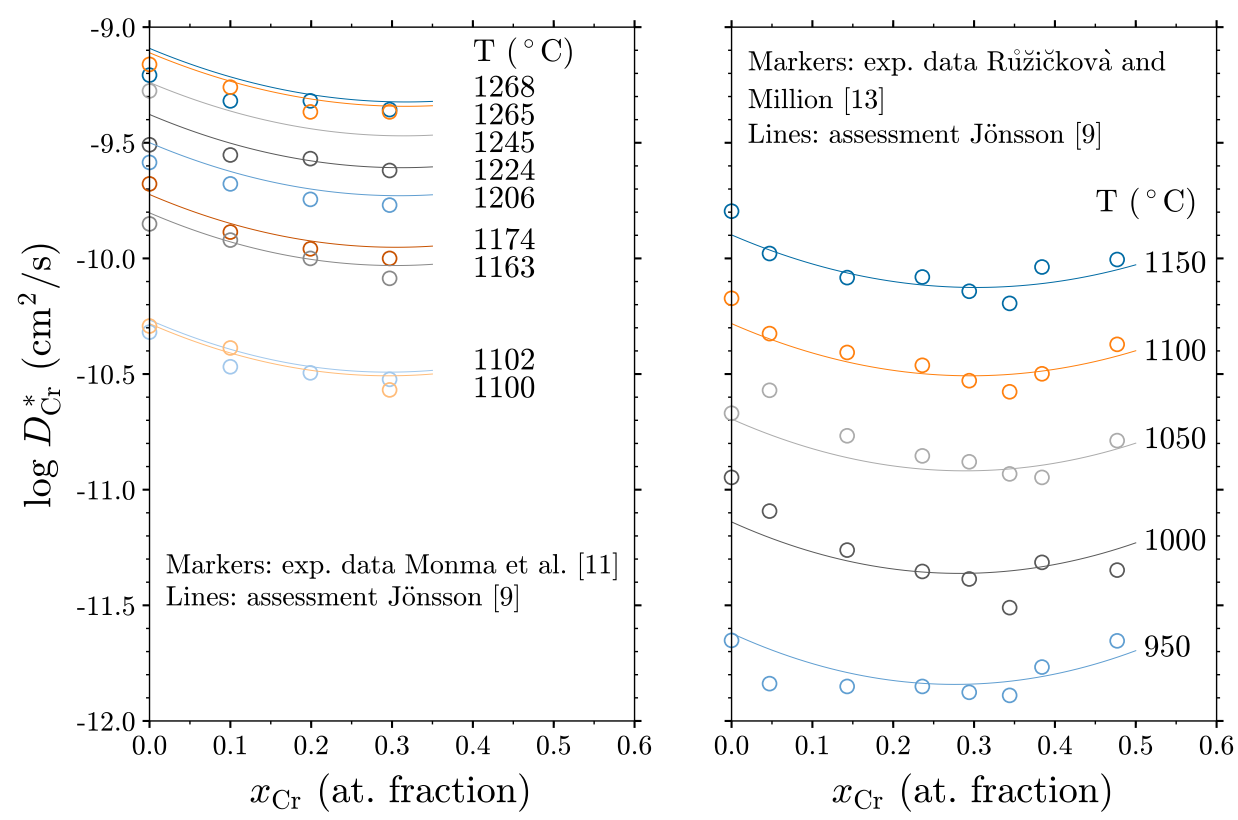

Figure 2: Composition dependence of the tracer diffusion coefficient of $\mathrm{Cr}$ in $\mathrm{Ni}-\mathrm{Cr}$ alloys from literature data (experimental results $[11,13]$ and mobility assessment [9]).
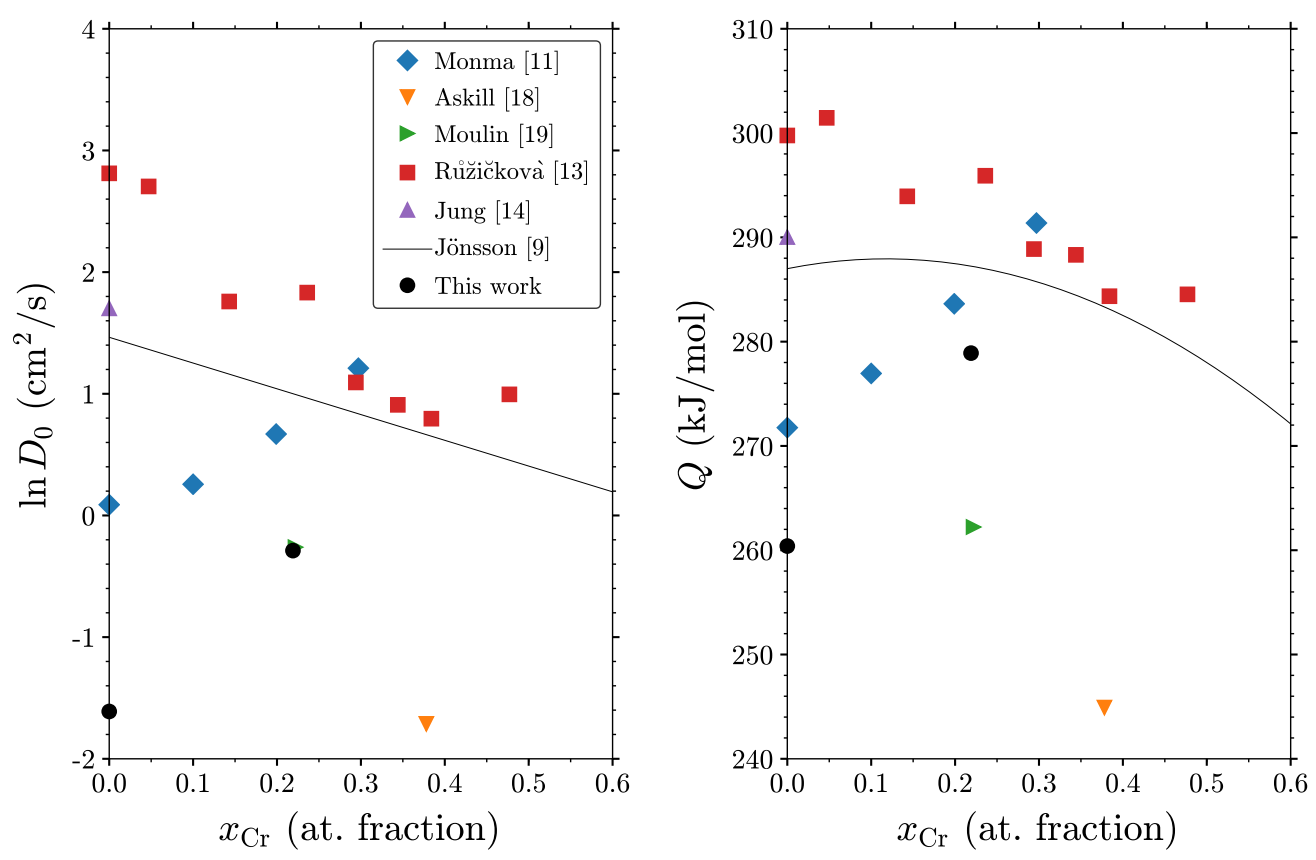

Figure 3: Composition dependence of the pre-exponential factor and activation energy for tracer diffusion of $\mathrm{Cr}$ in $\mathrm{Ni}-\mathrm{Cr}$ alloys, calculated from literature data. Solid lines drawn from Jönsson's assessment [9]. Present results added for comparison. 
and subjected to a recrystallization heat treatment for $20 \mathrm{~h}$ at $1075{ }^{\circ} \mathrm{C}$ in an argonbackfilled vacuum furnace. This produced coarse, equiaxed microstructures, with grains approximately $1 \mathrm{~mm}$ and $0.2 \mathrm{~mm}$ diameter for the $\mathrm{Ni}$ and $\mathrm{Ni}-22 \mathrm{Cr}$, respectively. Analysis by EBSD showed that the alloys had no particular crystallographic texture.

Prior to tracer deposition, the coupons were ground with $\mathrm{SiC}$ paper down to a P2000 grit, and polished with $9 \mu \mathrm{m}, 3 \mu \mathrm{m}$ and $1 \mu \mathrm{m}$ diamond suspensions. An automatic polishing machine was used to ensure reproducibility, and the procedure was set to minimize residual strain at the surface. Cross-section examination by TEM of a NiCr specimen prepared with this procedure showed that some surface work-hardening occurred, but the deformed layer was less than $30 \mathrm{~nm}$ deep.

Tracer deposition was done by sublimation in an Emitech K975X instrument. Chromium powder was placed in a Mo crucible facing the substrates in a chamber kept at $10^{-4}$ mbar, and an appropriate current was flown through the crucible, allowing $\mathrm{Cr}$ vapor to form and condense on the substrates. Depth-profile analysis by X-ray photoelectron spectroscopy (XPS) was used to measure the deposited film compositions and optimize the procedure. A current of $37 \mathrm{~A}$ was found to produce Cr films at a rate sufficiently low for the thickness to be kept small and controlled with reasonable accuracy. The oxygen level in the films was about 10-20 at. \% (the specimens were then sealed with Zr shavings, as described below, such that the residual oxygen was consumed by the $\mathrm{Zr}$ during the diffusion heat treatments). A built-in quartz balance was set to obtain $5 \mathrm{~nm}$ thick films. The $\mathrm{Ni}$ and $\mathrm{Ni}-22 \mathrm{Cr}$ substrates were coated with natural $\mathrm{Cr}$ (99.95\% pure, from Neyco, France) and ${ }^{54} \mathrm{Cr}$ (enriched at $99.8 \%$, from Euriso-top, France), respectively. The abundance of ${ }^{54} \mathrm{Cr}$ in natural $\mathrm{Cr}$ is 2.4 at. \%; as a consequence, the $\mathrm{Ni}-22 \mathrm{Cr}$ substrates contained 0.5 at. $\%{ }^{54} \mathrm{Cr}$.

\subsection{Diffusion heat treatments}

The specimens were vacuum-sealed in argon-backfilled quartz capsules together with $\mathrm{Zr}$ shavings, used as oxygen getter. At temperatures where both $\mathrm{Cr}$ and ${ }^{54} \mathrm{Cr}$ diffusion were studied, the $\mathrm{Ni}$ and $\mathrm{Ni}-22 \mathrm{Cr}$ specimens were placed together in the same capsule. The diffusion heat treatments were conducted in tube furnaces. To run an experiment, a furnace was first stabilized at the desired temperature, before introducing the quartz capsule in the hot zone. A quartz cap with a sleeve was then mounted so as to close the furnace tube while allowing temperature monitoring. This was done by placing a type $\mathrm{K}$ thermocouple in the sleeve, with its tip at the specimen level. To stop an experiment, the capsule was quickly pulled from the hot zone and allowed to cool on a metal tray, reaching room temperature in less than 5 $\min$.

Temperature-time profiles were used to determine effective diffusion times, $t_{\text {eff }}$, taking into account the heat-up and cool-down times, according to the method described by Rothman [20]:

$$
t_{\text {eff }}=\int_{0}^{t_{f}} \exp \left[-\frac{Q}{R}\left(\frac{1}{T(t)}-\frac{1}{T_{0}}\right)\right] \mathrm{d} t
$$

where $t_{f}$ is the end-time of the temperature recording (after cool-down) and $T_{0}$ the average temperature in the isotherm part of the temperature profile. The activation 
energy used in the calculation was $259 \mathrm{~kJ} / \mathrm{mol}$, which was the initial value obtained for $Q_{\mathrm{Cr}}^{\mathrm{Ni}}$, with uncorrected diffusion times. The corrections were very small $(200 \mathrm{~s}$ typically) so that the updated $Q_{\mathrm{Cr}}^{\mathrm{Ni}}, 260 \mathrm{~kJ} / \mathrm{mol}$, was very close to the initial value, and no further iteration was necessary.

The retained temperature was obtained from $T_{0}$ after calibration. The standard uncertainty on temperatures was estimated to be $1.7^{\circ} \mathrm{C}$ in the range of interest (see calibration procedure and uncertainty estimation in Appendix A).

\subsection{Concentration profile measurements}

Intensity-depth profiles were measured by SIMS using a Cameca IMS $7 \mathrm{f}$ instrument. A duoplasmatron $\mathrm{O}_{2}^{+}$source was used, with an impact energy of $5 \mathrm{keV}$ and primary current of $200 \mathrm{nA}$, collecting positive secondary ions. The raster area was $150 \times$ $150 \mu \mathrm{m}$, and the analysis area 8 or $33 \mu \mathrm{m}$ diameter. Oxygen flooding was used to reduce roughness development during sputtering.

The following isotopes were recorded: ${ }^{16} \mathrm{O},{ }^{50} \mathrm{Cr},{ }^{52} \mathrm{Cr},{ }^{54} \mathrm{Cr},{ }^{58} \mathrm{Ni}$ and ${ }^{64} \mathrm{Ni}$. Profiles in $\mathrm{Cr} / \mathrm{Ni}$ specimens were processed using the ${ }^{52} \mathrm{Cr}$ signal normalized by the ${ }^{64} \mathrm{Ni}$ signal, in order to compensate for instrument variations - ${ }^{64} \mathrm{Ni}$ was used rather than the more abundant ${ }^{58} \mathrm{Ni}$ because the latter would occasionally saturate the detector. Signals used for the determination of diffusion coefficients were such that the $\mathrm{Cr}$ concentration was below 1 at. \%. A linear relation was assumed between intensities and concentrations, and all processing was done from intensity-depth profiles. In the case of ${ }^{54} \mathrm{Cr} / \mathrm{Ni}-22 \mathrm{Cr}$ specimens, we used $I\left({ }^{54} \mathrm{Cr}\right) / I\left({ }^{64} \mathrm{Ni}\right)$. Due to the relatively high ${ }^{54} \mathrm{Cr}$ background level in $\mathrm{Ni}-22 \mathrm{Cr}$, the ${ }^{54} \mathrm{Cr}$ concentrations used for processing were between 1 and 10 at. \%. In this range, the SIMS response presents some degree of non-linearity, which limits the reliability of the results, as discussed subsequently.

\subsection{Crater depth measurements}

The sputtering crater depths were measured by contact profilometry with a Bruker Dektak 8 instrument, calibrated with a reference $1 \mu \mathrm{m}$ step. Sputtering times $\left(t_{s}\right)$ were then converted to depths $(z)$ assuming a constant sputtering rate $\left(r_{s}\right)$ throughout a given profile. The standard uncertainty on depths was estimated by the rootmean-square roughness at the bottom of the craters (i.e., the standard deviation of the depth distribution), on average $14 \mathrm{~nm}$. Specifically, in the linear regression of intensity-depth profiles, the uncertainty on $z$ was assumed to vary linearly with $z$, from the surface roughness $(5 \mathrm{~nm})$ to the crater bottom roughness.

It is noted that in most cases, the deposited Cr film was entirely consumed by diffusion into the substrates, such that there was no film left and no film/substrate interface to sputter in the SIMS analysis of the post-diffusion specimens. It follows that the depth resolution function was reduced to the contribution of the crater roughness, which was taken into account as described above (with SIMS, the information depth is limited to 1-2 monolayers and the atomic mixing to a few $\mathrm{nm}$ [21], such that the crater roughness contribution predominates in the depth resolution function).

For completeness, the sputtering rate was on average $\overline{r_{s}}=0.68 \pm 0.08 \mathrm{~nm} / \mathrm{s}$ ( \pm one standard deviation) from 60 craters. Among profiles recorded in different 
Table 2: Experimental parameters and diffusion coefficients ( \pm one standard uncertainty) obtained in the study of $\mathrm{Cr}$ diffusion in $\mathrm{Ni}$ and $\mathrm{Ni}-22 \mathrm{Cr}$ (diffusion distance calculated from present $\mathrm{Cr} / \mathrm{Ni}$ data).

\begin{tabular}{lcccc}
\hline$T\left({ }^{\circ} \mathrm{C}\right)$ & $t(\mathrm{~h})$ & $2 \sqrt{D^{*} t}(\mathrm{~nm})$ & \multicolumn{2}{c}{$D^{*}\left(\mathrm{~cm}^{2} / \mathrm{s}\right)$} \\
\cline { 4 - 5 } & & & $\mathrm{Cr}$ in Ni & $\mathrm{Cr}$ in Ni-22Cr \\
\hline 843 & 2 & 634 & $(1.4 \pm 0.2) \times 10^{-13}$ & \\
789 & 1 & 211 & $(3.1 \pm 0.2) \times 10^{-14}$ & $(1.6 \pm 0.3) \times 10^{-14}$ \\
748 & 3 & 207 & $(9.9 \pm 0.4) \times 10^{-15}$ & $(4.0 \pm 0.9) \times 10^{-15}$ \\
704 & 8 & 139 & $(1.7 \pm 0.2) \times 10^{-15}$ & $(6.8 \pm 1.7) \times 10^{-16}$ \\
668 & 22 & 166 & $(8.7 \pm 0.7) \times 10^{-16}$ & \\
635 & 162 & 209 & $(1.9 \pm 0.1) \times 10^{-16}$ & $(7.7 \pm 2.1) \times 10^{-17}$ \\
600 & 309 & 145 & $(4.7 \pm 0.5) \times 10^{-17}$ & \\
565 & 984 & 145 & $(1.5 \pm 0.1) \times 10^{-17}$ & $(3.9 \pm 1.8) \times 10^{-18}$ \\
542 & 5273 & 167 & $(3.7 \pm 0.2) \times 10^{-18}$ & $(9.3 \pm 3.8) \times 10^{-19}$ \\
\hline
\end{tabular}

grains on a given specimen, slope variations on a $\left(t_{s}, \ln I\right)$ plot (due to both sputtering rate variations and diffusivity variations) were greater than slope variations on a $(z, \ln I)$ plot (reflecting diffusivity variations only), i.e., the sputtering rate was more sensitive to grain orientation than was the diffusivity. As a consequence, sputtering times were converted to depths using individual $r_{s}$ values, i.e., measured on each individual crater.

\subsection{Experimental conditions and data processing}

Diffusion times and temperatures were chosen so as to keep the diffusion distance approximately constant. Testing led us to aim for $2 \sqrt{D^{*} t}=150-200 \mathrm{~nm}$ in order to avoid polishing-induced deformation in the near-surface region and to collect enough data points for the profile shapes to be well defined (see Section 4). Given this target, the diffusion times and temperatures were set so that experiments would be at least 10 times longer than the time required for the specimens to cool down, and shorter than a year. The experimental conditions are summarized in Table 2.

In most cases, the Cr film was entirely consumed by diffusion into the substrate. The resulting concentration profiles may then be studied with the "thin-film" or "instantaneous source" solution of the diffusion equation [22]:

$$
C(z, t)=\frac{q}{\sqrt{\pi D^{*} t}} \exp \left(-\frac{z^{2}}{4 D^{*} t}\right)
$$

where $q$ is the quantity of tracer per unit area. In practice, the source is not actually instantaneous but persists for some (unknown) time, during which it maintains a constant concentration at the surface. Therefore, the concentration profiles have a more complex time evolution, with two limiting cases being Eq. (4) and the constantconcentration solution [22]:

$$
\frac{C(z, t)}{C_{s}}=\operatorname{erfc}\left(\frac{z}{2 \sqrt{D^{*} t}}\right)
$$


where $C_{s}$ is the surface concentration. Rothman [20] discussed this case, giving a mixed solution and also noting that at large depths, the erfc contribution approached a gaussian. An inherent difficulty with solutions containing an erfc term is that unlike logarithms, the erfc function does not transform products into sums. In principle, Eq. (5) can be linearized if $C_{s}$ is known. When working from intensity-depths profiles, with intensities proportional to concentrations, a value for the proportionality constant is required too. In practice, this would involve adjusting a constant $k$ to achieve linearity in a $\left(z, \operatorname{erfc}^{-1}(k \cdot I)\right)$ plot, which would add a source of error.

A sensible approach, then, is to use the thin-film solution and estimate the uncertainty associated with this choice of boundary condition. This was done as follows. Each profile was plotted in the form $\left(z^{2}, \ln I\right)$, from which an appropriate depth range was selected for fitting. A linear model was fitted to the selected data to obtain $D^{*}$ as $D^{*}=-\frac{1}{4 a t}$, where $a$ is the adjusted slope. Specifically, an orthogonal distance regression (ODR) method was used, so as to take into account the uncertainty on both depth and intensity in estimating the uncertainty associated with the slope. This was done using the scipy.odr [23] Python module.

Then, for a given set of conditions $\left\{t, T, D^{*}\right\}$, a profile was generated with the constant-concentration solution, Eq. (5). This virtual profile was then fitted with the thin-film solution, which produced a diffusion coefficient noted $D_{\text {mixed }}^{*}$. The error $\left|D^{*}-D_{\text {mixed }}^{*}\right|$ represents an upper limit on the error made by choosing the thin film solution to fit an experimental profile in these conditions $\left\{t, T, D^{*}\right\}$. It is important that the virtual profile be fitted in the same depth range that was used to fit the experimental profile, since the error depends on the depth range (it vanishes at large depths). Here, relative errors were between $6 \%$ and $11 \%$ for the ${ }^{52} \mathrm{Cr} / \mathrm{Ni}$ profiles, and 20 to $29 \%$ for the ${ }^{54} \mathrm{Cr} / \mathrm{Ni}-22 \mathrm{Cr}$ profiles (the latter were fitted at smaller depths, see Section 4.1). As noted above, the actual boundary condition is somewhere in between the thin-film and constant-concentration conditions. Assuming a uniform probability distribution, the uncertainty associated with the choice of the thin-film solution was estimated as $\left|D^{*}-D_{\text {mixed }}^{*}\right| / \sqrt{3}$.

\section{Results and discussion}

\subsection{Tracer diffusion coefficients}

Typical intensity-depth profiles obtained after diffusion of $\mathrm{Cr}$ in $\mathrm{Ni}$ are shown in Fig. 4. Tracer diffusion coefficients were determined by linear regression of the $\left(z^{2}, \ln I\left({ }^{52} \mathrm{Cr}\right) / I\left({ }^{64} \mathrm{Ni}\right)\right)$ data, as indicated above. For each temperature, average values of $D^{*}$ were determined from 3 profiles measured in 3 different grains; these are given in Table 2 . Uncertainties on the $D^{*}$ values were calculated by combining the uncertainty associated with the slope of each profile (accounting for the uncertainty on the crater depth, SIMS intensity, and dispersion of the data points), the uncertainty associated with the choice of boundary condition and the standard deviation on the 3 values used in the average. These three sources of uncertainty were of similar amplitude. They were combined assuming no correlation. On average, the relative combined uncertainty on $D^{*}$ was $8 \%$.

In order to test the effect of the diffusion distance on the reliability of the result, two tests were done at $668{ }^{\circ} \mathrm{C}$, with durations of $22 \mathrm{~h}\left(2 \sqrt{D^{*} t}=166 \mathrm{~nm}\right)$ and $3 \mathrm{~h}$ $\left(2 \sqrt{D^{*} t}=61 \mathrm{~nm}\right)$. The diffusion coefficient obtained after $3 \mathrm{~h}$ heat treatment was 

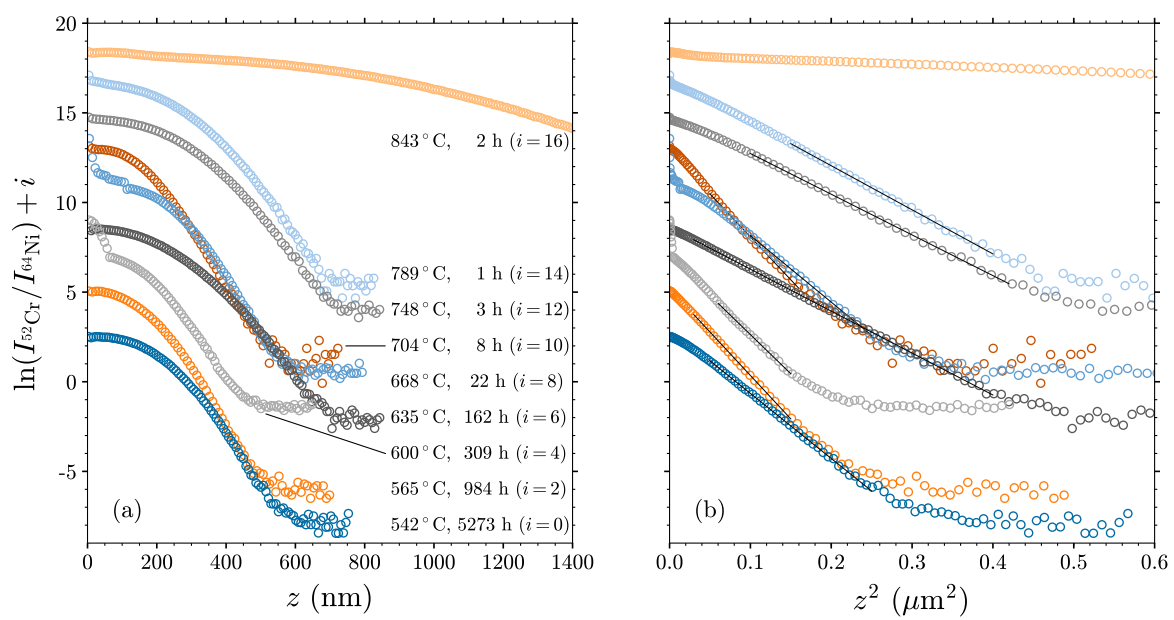

Figure 4: Volume diffusion profiles for $\mathrm{Cr}$ in $\mathrm{Ni}$, plotted as a function of (a) $z$ and (b) $z^{2}$. Offsets $i$ were added to distinguish the profiles. In (b), the lines of best fit used to determine diffusion coefficients are superimposed.

2.3 times higher than that obtained after $22 \mathrm{~h}$. This difference is too large to be due to a grain orientation effect (the standard deviation on the 3 profiles was $7 \%$ in each case, and the material had no cristallographic texture), and it is much larger than the combined uncertainty. It is concluded that the diffusion distance after $3 \mathrm{~h}$ heat treatment was too short to establish a reliable concentration profile. This value was dismissed, and the other heat treatments were done so that diffusion distances would be at least $150 \mathrm{~nm}$.

In the case of ${ }^{54} \mathrm{Cr}$ diffusion in $\mathrm{Ni}-22 \mathrm{Cr}$, the available signal range was much reduced due to the high background ${ }^{54} \mathrm{Cr}$ level in the substrate, as shown in Fig. 5. This range corresponds to ${ }^{54} \mathrm{Cr}$ concentrations of $1-10 \%$, where the SIMS response deviates from linearity. Furthermore, at these levels, ${ }^{54} \mathrm{Cr}-{ }^{54} \mathrm{Cr}$ interactions become significant - that is, conditions switch from those of impurity diffusion (infinite dilution) to those of interdiffusion. However, mobilities and thermodynamic interactions in the Ni-rich solution are such that the interdiffusion coefficient is not vastly different from the $\mathrm{Cr}$ tracer coefficient. As is shown in Appendix B, the quantity determined from the ${ }^{54} \mathrm{Cr}$ intensity profiles slightly overestimates the true tracer coefficient of $\mathrm{Cr}$ in $\mathrm{Ni}-22 \mathrm{Cr}$.

The $\left(D_{\mathrm{Cr}}^{*}\right)^{\mathrm{Ni}-22 \mathrm{Cr}}$ values obtained by linear regression of the $\left(z^{2}, \ln I\left({ }^{54} \mathrm{Cr}\right) / I\left({ }^{64} \mathrm{Ni}\right)\right)$ data are consistently lower than the $\left(D_{\mathrm{Cr}}^{*}\right)^{\mathrm{Ni}}$ values, as shown in Fig. 6. It is concluded that in the temperature range investigated, $\mathrm{Cr}$ diffusion is slower in $\mathrm{Ni}-22 \mathrm{Cr}$ than it is in Ni. This is in agreement with the results of Monma et al. [11] and Rưžičková and Million [13] (Fig. 2).

The present results are compared with the available literature data in Fig. 1. Our values are seen to be in good agreement with the higher temperature data, and with Jönsson's assessment [9]. For both $\left(D_{\mathrm{Cr}}^{*}\right)^{\mathrm{Ni}}$ and $\left(D_{\mathrm{Cr}}^{*}\right)^{\mathrm{Ni}-22 \mathrm{Cr}}$, the activation energy would appear to be slightly smaller in the present work, compared to the literature: this is discussed in the next Section. 


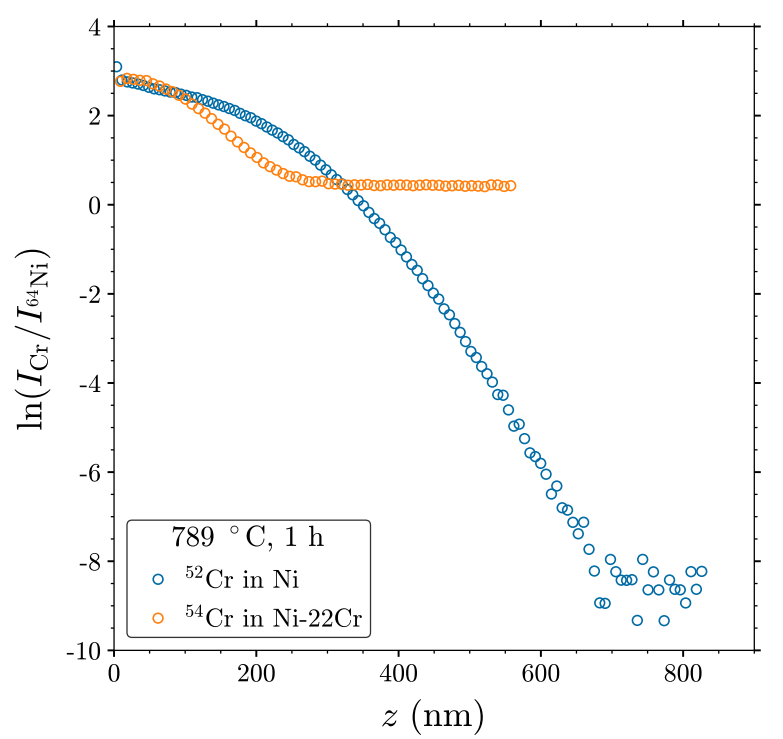

Figure 5: Volume diffusion profiles obtained for $\mathrm{Cr} / \mathrm{Ni}$ and $\mathrm{Cr} / \mathrm{Ni}-22 \mathrm{Cr}$ systems after $1 \mathrm{~h}$ at $789{ }^{\circ} \mathrm{C}$. The high background ${ }^{54} \mathrm{Cr}$ level in $\mathrm{Ni}-22 \mathrm{Cr}$ limits the available intensity range in this system.

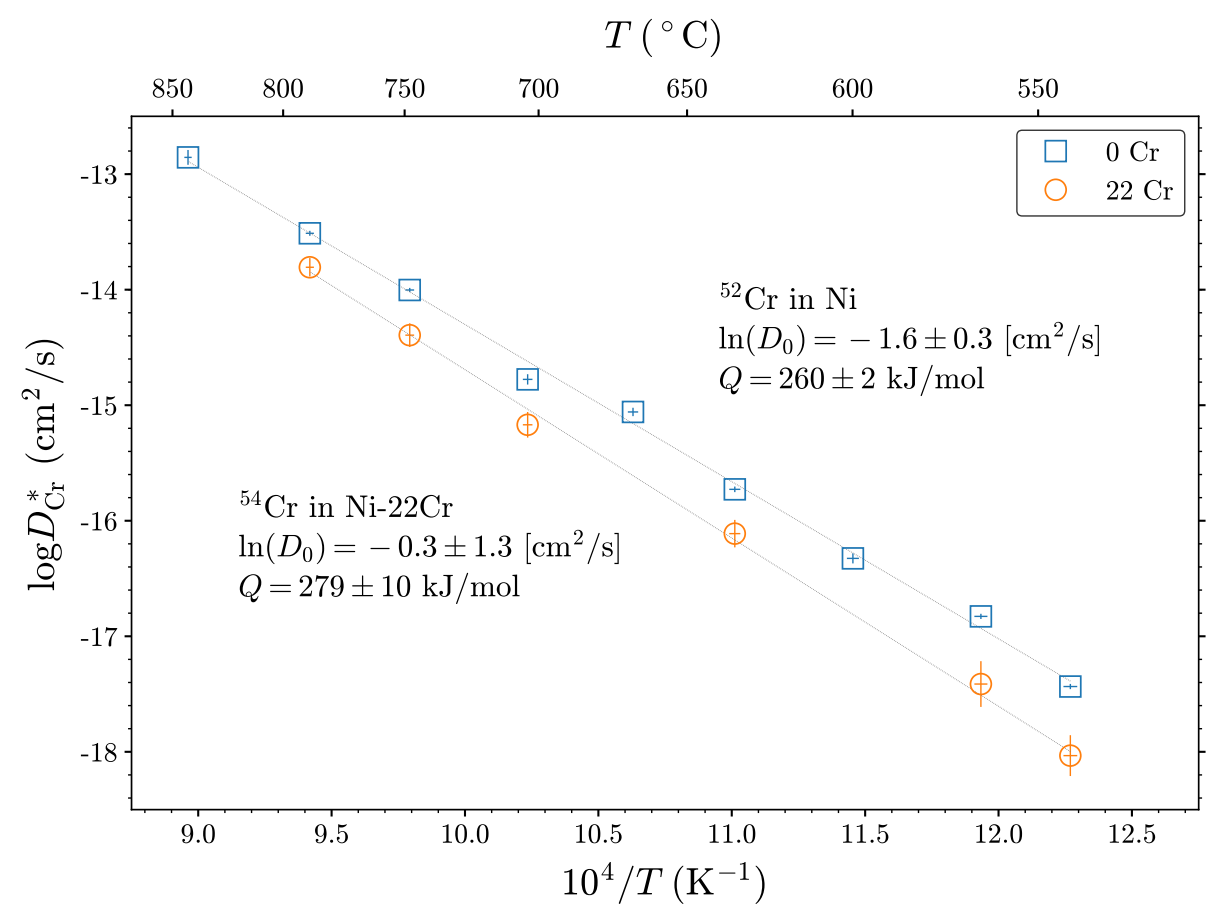

Figure 6: Diffusion coefficients obtained for $\mathrm{Cr}$ in $\mathrm{Ni}$ and in $\mathrm{Ni}-22 \mathrm{Cr}$. The error bars represent \pm one standard uncertainty (see details in text). The dotted lines represent the best fit of Eq. (2) to each series, and the corresponding parameters are indicated. 


\subsection{Mobility parameters}

As shown in Fig. 6, no deviation from Arrhenius behavior is observed for either data series obtained in the present work. Mobility parameters $\ln \left(D_{0}\right)$ and $Q$ were determined by fitting Eq. (2) to each series. The adjusted values are $\ln \left(D_{0}\right)=$ $-1.6 \pm 0.3\left[\mathrm{~cm}^{2} / \mathrm{s}\right], Q=260 \pm 2 \mathrm{~kJ} / \mathrm{mol}$ for $\mathrm{Cr}$ in $\mathrm{Ni}$, and $\ln \left(D_{0}\right)=-0.3 \pm 1.3$ $\left[\mathrm{cm}^{2} / \mathrm{s}\right], Q=279 \pm 10 \mathrm{~kJ} / \mathrm{mol}$ for $\mathrm{Cr}$ in Ni-22Cr ( \pm one standard uncertainty). The ODR method was again used to account for the uncertainties on $T$ and $D^{*}$ in estimating the uncertainties on $\ln \left(D_{0}\right)$ and $Q$. Using the present values of $\ln \left(D_{0}\right)$ and $Q$, the temperature for which $\left(D_{\mathrm{Cr}}^{*}\right)^{\mathrm{Ni}}=\left(D_{\mathrm{Cr}}^{*}\right)^{\mathrm{Ni}-22 \mathrm{Cr}}$ is calculated to be $1449{ }^{\circ} \mathrm{C}$, which is close to the melting point of nickel $\left(T_{m}=1455^{\circ} \mathrm{C}\right)$, as could be expected.

Diffusion of $\mathrm{Cr}$ in $\mathrm{Ni}$ was studied by ab initio methods by Tucker et al. [24]. Their calculations showed that vacancy-solute exchange was the dominant diffusion mechanism above $187^{\circ} \mathrm{C}$. The tracer coefficient of $\mathrm{Cr}$ was predicted to display nonArrhenius behavior, with the pre-exponential factor decreasing as the temperature decreased - the temperature dependence was attributed mostly to variations of the correlation factor, with lesser contributions from electronic excitations due to vacancy migration and binding. However, the deviation from Arrhenius behavior was predicted to be significant only at temperatures lower than those investigated here, with the error made on $D^{*}$ when considering a constant $D_{0}$ being less than 10 $\%$ (i.e., within experimental error) above $540{ }^{\circ} \mathrm{C}$. It follows that the present results are consistent with the ab initio calculations, but obviously measurements at even lower temperatures are needed to evaluate the validity of the predicted trends.

Obtaining reliable data at lower temperatures would require measuring intensitydepth profiles over smaller diffusion distances. In the present work, this was not limited by the depth resolution of the SIMS technique in itself, but rather by the ability to produce strain-free surfaces with no tracer left after the diffusion heat treatment, i.e., to produce a thinner tracer film to start with (when it is present, sputtering through the remaining film produces interface mixing and lowers the effective depth resolution). This can be achieved by combining plasma or ion cleaning of the surface and film deposition in a high vacuum chamber, or, alternatively, by using an aqueous-based deposition process after electrolytic polishing or vacuum annealing, as done in some radiotracer studies.

As shown in Fig. 3, the present $\ln \left(D_{0}\right)$ and $Q$ values are in the lower range of the values determined from previous studies at higher temperatures. Specifically, $Q_{\mathrm{Cr}}^{\mathrm{Ni}}$ $(260 \mathrm{~kJ} / \mathrm{mol})$ is in good agreement with the value obtained by Monma et al. [11] $(272 \mathrm{~kJ} / \mathrm{mol})$, but significantly smaller than those obtained with the data by Jung et al. [14] (290 kJ/mol) and Růžičková and Million [13] $(300 \mathrm{~kJ} / \mathrm{mol})$. If the latter values are reliable estimations of the high temperature diffusivity, the variance observed here could reflect a decrease of $\left(D_{0}\right)_{\mathrm{Cr}}^{\mathrm{Ni}}$ with decreasing temperature, as predicted in Ref. [24] (assuming a constant $D_{0}$ would affect the partitioning between $D_{0}$ and $Q$, and would therefore affect the value of both parameters). However, the uncertainty in the quoted experimental studies is not known, the number of studies is small, and the scatter in and values between these studies is relatively large, which precludes a definitive conclusion at this point. It is noted that when comparing the present work and Refs. $[11,13,14]$, larger $Q_{\mathrm{Cr}}^{\mathrm{Ni}}$ values are always accompanied by larger $\left(D_{0}\right)_{\mathrm{Cr}}^{\mathrm{Ni}}$ values. The variations are such that overall, the $\left(D_{\mathrm{Cr}}^{*}\right)^{\mathrm{Ni}}$ values are all in good agreement. This is shown in Fig. 1(a), where the present results are plotted 
alongside the literature data.

With regards to the composition dependence, we find both $D_{0}$ and $Q$ to be slightly higher for $\mathrm{Cr}$ diffusion in $\mathrm{Ni}-22 \mathrm{Cr}$ than for $\mathrm{Cr}$ diffusion in $\mathrm{Ni}$. This positive dependence on the $\mathrm{Cr}$ concentration is consistent with Monma et al.'s data [11], and at variance with Růžičková and Million's [13].

Variations between studies can arise from a number of sources, such as differences in substrate purity. The data sets of interest were obtained from different experimental techniques and data processing methods, which would inevitably produce some scatter in absolute values of the diffusion coefficients, and therefore in the pre-exponential factors. On the other hand, this type of bias should cancel out when considering the activation energy. The dispersion of $Q$ values may perhaps be due to issues with temperature control during the diffusion heat treatments in some of the studies.

In discussing the best choice of $\mathrm{Cr}$ mobility parameters, it is worth noting that the values retained by Jönsson [9] for the end-members ( $\mathrm{Cr}$ in fcc-Ni and $\mathrm{Cr}$ in a virtual fcc-Cr) may be viewed as somewhat arbitrary: $Q_{\mathrm{Cr}}^{\mathrm{Ni}}$ was taken equal to $Q_{\mathrm{Ni}}^{\mathrm{Ni}}$ (the reason was not specified, but presumably because only two reliable Cr impurity diffusion studies were available at the time and showed somewhat conflicting $Q_{\mathrm{Cr}}^{\mathrm{Ni}}$ values, while a large number of Ni self-diffusion studies pointed to a consistent $\left.Q_{\mathrm{Ni}}^{\mathrm{Ni}}\right)$. Since it is not experimentally accessible, $Q_{\mathrm{Cr}}^{\mathrm{fcc}-\mathrm{Cr}}$ was calculated from empirical relationships. A binary interaction parameter was used to describe the composition dependence of $Q_{\mathrm{Cr}}^{\mathrm{NiCr}}$, although the data and weights used for fitting were not specified, nor was the choice of including an interaction parameter commented. Judging from the scatter in Fig. 3, it did not seem necessary (note that several $Q_{\mathrm{Cr}}^{\mathrm{NiCr}}$ values reported in Table 1 are not included in Fig. 3, as they would be off-chart by far). Similar remarks can be made about the $D_{0}$ assessment. We conclude that more experimental data are needed to establish a reliable trend as to the composition dependence of $D_{0}$ and $Q$ in for Cr diffusion in fcc $\mathrm{Ni}-\mathrm{Cr}$, with an even greater need for measurements below $550{ }^{\circ} \mathrm{C}$.

To serve practical purposes, the study of low temperature diffusivity should be extended to the $\mathrm{Ni}-\mathrm{Fe}-\mathrm{Cr}$ system, which forms the basis for many austenitic alloys. High temperature data were obtained by several groups, including in a range of Ferich ternary alloys $[25,26]$ and in the Ni-base alloy Inconel 600 [27-29]. The quoted papers report activation energies of $250-310 \mathrm{~kJ} / \mathrm{mol}$, in the range of the $Q_{\mathrm{Cr}}^{\mathrm{NiCr}}$ values in Fig. 3. In the extensive study by Million et al. [26], the composition dependence of the activation energy could not be described by a simple relationship, and it was rather weak in any case.

\section{Conclusion}

The pre-exponential factors and activation energies for $\mathrm{Cr}$ diffusion in $\mathrm{Ni}$ and in $\mathrm{Ni}-22 \mathrm{Cr}$ at $542-843{ }^{\circ} \mathrm{C}$ were found to be consistent with higher temperature data. The lack of a deviation from Arrhenius behavior is also in agreement with available ab initio calculations. Such a deviation was predicted to become significant at lower temperatures, however, which remains to be evaluated experimentally.

The diffusion of $\mathrm{Cr}$ was found to be slightly slower in $\mathrm{Ni}-22 \mathrm{Cr}$ than in $\mathrm{Ni}$, also in agreement with experimental data at higher temperatures. Both the pre-exponential 
factor and activation energy showed a slightly positive dependence on $\mathrm{Cr}$ concentration.

Overall, considering $\mathrm{Cr}$ diffusion in $\mathrm{Ni}-\mathrm{Cr}$, and in Ni-rich and Fe-rich ternary solutions, variations of the activation energy with substrate composition appear to be small (no greater than the scatter between laboratories for a given composition). This is not unexpected given the chemical proximity of $\mathrm{Ni}, \mathrm{Fe}$ and $\mathrm{Cr}$ - also reflected in the fact that in a given alloy, values of $D_{\mathrm{Ni}}^{*}, D_{\mathrm{Fe}}^{*}$ and $D_{\mathrm{Cr}}^{*}$ are generally within a factor of 3 from each other, and activation energies for the three elements are similar. Although verification is needed, the present results would suggest that mobility parameters extracted from high temperature measurements for the three elements in ternary alloys remain valid down to $542{ }^{\circ} \mathrm{C}$.

\section{Disclaimer}

This article reflects only the author's view and the European Commission is not responsible for any use that may be made of the information it contains.

\section{Declaration of interests}

The authors declare that they have no known competing financial interests or personal relationships that could have appeared to influence the work reported in this paper.

\section{Acknowledgements}

This project has received funding from the Euratom research and training programme 2014-2018 under Grant Agreement N 661913 (SOTERIA project). The authors would like to thank C. Guerre (CEA/DEN/SCCME) for providing the Cr powders, P. Bonnaillie and A. Morellec (CEA/DEN/SRMP) for performing the recrystallization heat treatments, S. Bosonnet and K. Ginestar (CEA/DEN/SCCME) for their help setting up the diffusion heat treatments, and F. Miserque (CEA/DEN/SCCME) for performing the XPS analysis used in optimizing the Cr deposition process.

\section{Appendix A Uncertainty on diffusion heat treatment temperatures}

The thermocouple and recording apparatus used to monitor specimen temperatures during the diffusion heat treatments were calibrated using a reference apparatus (thermocouple and reader) certified by the Laboratoire national de métrologie et d'essais (France), with a standard uncertainty of $1.5{ }^{\circ} \mathrm{C}$ in the temperature range of interest. Specifically, a series of temperature measurements were done with both thermocouples in the same furnace. The values given by the regular and reference apparatus are noted $\tau_{i}$ and $T_{i}$, respectively. Here $\tau$ is an independent variable, and $T$ gives an estimation of the true furnace temperature: $T_{i}=E\left(\tau_{i}\right)+\epsilon_{i}$, where the error $\epsilon$ is assumed to follow a zero-mean normal distribution, $\epsilon=N\left(0, \sigma_{\epsilon}\right)$. An estimation $u_{\text {ref }}$ of the uncertainty $\sigma_{\epsilon}$ is known $\left(u_{\text {ref }}=1.5^{\circ} \mathrm{C}\right)$. The regression equation is

$$
\hat{T}=a+b \tau
$$


where $\hat{T}$ is the calibrated temperature, and $a$ and $b$ the estimators of the true coefficients, determined through a least-squares method. The uncertainty associated with the future prediction of a calibrated temperature $\hat{T}_{0}$ from a measured temperature $\tau_{0}$ is estimated by:

$$
u_{\text {calib }}=s_{e} \sqrt{1+\frac{1}{n}+\frac{\left(\tau_{0}-\bar{\tau}\right)^{2}}{\sum_{i=1}^{n}\left(\tau_{i}-\bar{\tau}\right)^{2}}}
$$

where $n$ is the number of measurements done during calibration $(n=8), \bar{\tau}$ the mean of the $\tau_{i}$ series, and $s_{e}$ is the estimated standard error:

$$
s_{e}=\sqrt{\frac{1}{n-2} \sum_{i=1}^{n}\left(T_{i}-\hat{T}_{i}\right)^{2}}
$$

The quantity $u_{\text {calib }}$ reflects the uncertainty on the adjusted parameters $a$ and $b$, due to the dispersion of the calibration points $\left(\tau_{i}, T_{i}\right)$. It depends on the future measurement, $\tau_{0}$, but weakly; an average $u_{\text {calib }}=0.3{ }^{\circ} \mathrm{C}$ is obtained.

During a diffusion heat treatment, considering the experimental procedure and the furnace temperature profile, the specimen temperature is measured with an estimated $1{ }^{\circ} \mathrm{C}$ precision, i.e., the measurements are all within $\pm 1{ }^{\circ} \mathrm{C}$ of the actual specimen temperature. Assuming a normal distribution, this yields a standard uncertainty of $u_{\mathrm{loc}}=0.3{ }^{\circ} \mathrm{C}$. Monitoring over the longest heat treatment (over 7 months, sampling every minute) yielded a standard deviation of $u_{\text {time }}=0.7^{\circ} \mathrm{C}$. Finally, considering that the different uncertainties are non-correlated, the combined standard uncertainty on temperatures is:

$$
u_{\mathrm{c}}=\sqrt{u_{\mathrm{ref}}^{2}+u_{\text {calib }}^{2}+b^{2} u_{\mathrm{loc}}^{2}+b^{2} u_{\text {time }}^{2}}=1.7^{\circ} \mathrm{C}
$$

\section{Appendix B Tracer and interdiffusion coefficients}

In the binary $\mathrm{Ni}-\mathrm{Cr}$ system, the interdiffusion coefficient $\tilde{D}$ is given by the Darken expression [22]:

$$
\tilde{D}=\left(x_{\mathrm{Ni}} D_{\mathrm{Cr}}^{*}+x_{\mathrm{Cr}} D_{\mathrm{Ni}}^{*}\right) \cdot S \cdot \phi
$$

with $S$ the vacancy-wind factor and $\phi$ the thermodynamic factor in the fcc $\mathrm{Ni}-\mathrm{Cr}$ solution. The vacancy-wind factor can be calculated based on the random-alloy model by Manning $[22,30]$ :

$$
S=1+\frac{1-f_{0}}{f_{0}} \frac{x_{\mathrm{Ni}} x_{\mathrm{Cr}}\left(D_{\mathrm{Ni}}^{*}-D_{\mathrm{Cr}}^{*}\right)^{2}}{\left(x_{\mathrm{Ni}} D_{\mathrm{Ni}}^{*}+x_{\mathrm{Cr}} D_{\mathrm{Cr}}^{*}\right)\left(x_{\mathrm{Ni}} D_{\mathrm{Cr}}^{*}+x_{\mathrm{Cr}} D_{\mathrm{Ni}}^{*}\right)}
$$

with $f_{0}=0.7815$ for an fcc lattice. The thermodynamic factor may be written:

$$
\phi=\frac{x_{\mathrm{Cr}}}{R T} \frac{\partial \mu_{\mathrm{Cr}}}{\partial x_{\mathrm{Cr}}}
$$

with $\mu_{\mathrm{Cr}}$ the chemical potential of $\mathrm{Cr}$. The interdiffusion coefficient was calculated at the temperatures of interest using the thermodynamic assessment by Lee [31] and the mobility assessment by Jönsson [9]. This, of course, assumes that both sets of parameters can be extrapolated to low temperatures. The present results 

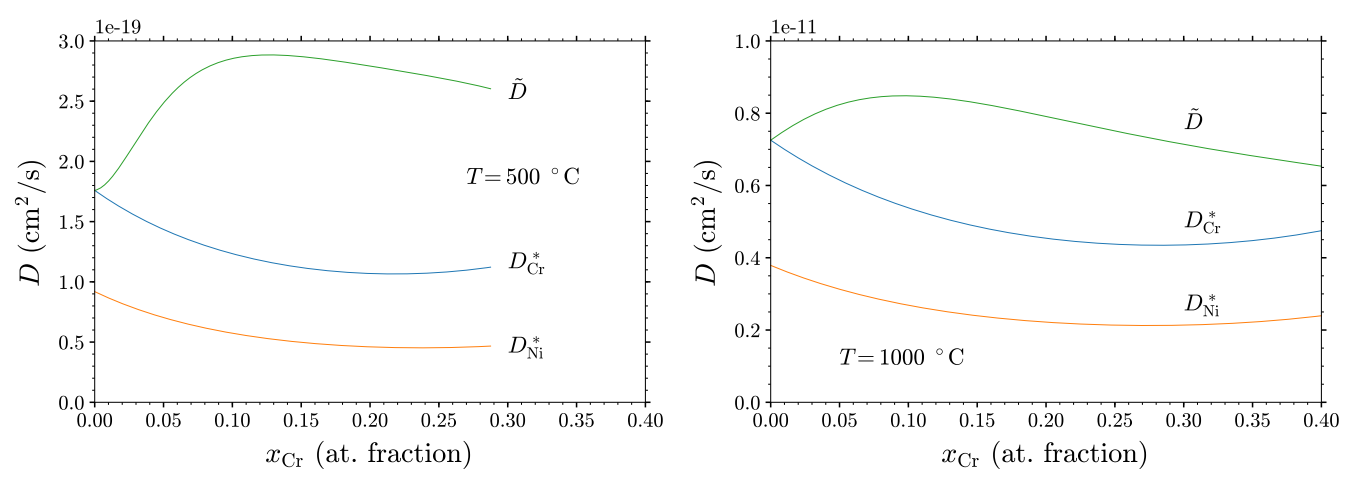

Figure B1: Tracer and interdiffusion coefficients in the Ni-rich fcc solid solution of the $\mathrm{Ni}-\mathrm{Cr}$ system at 500 and $1000{ }^{\circ} \mathrm{C}$, from the thermodynamic assessment of Lee [31] and the mobility assessment of Jönsson [9].

indicate that the extrapolation is acceptable for the Cr mobility parameters. Nickel mobility parameters are also constant down to $500{ }^{\circ} \mathrm{C}$ [16]. In the temperature range 500-1000 ${ }^{\circ} \mathrm{C}$ and the $\mathrm{Cr}$ concentration range $0-20$ at. \%, $S$ takes values between 1 and 1.03: its contribution is negligible, due to and $D_{\mathrm{Cr}}^{*}$ and $D_{\mathrm{Ni}}^{*}$ being of similar magnitudes.

Interdiffusion and tracer coefficients calculated at 500 and $1000{ }^{\circ} \mathrm{C}$ are plotted in Fig. B1. At the temperatures and compositions of interest, $\tilde{D}$ is larger than $D_{\mathrm{Cr}}^{*}$. The $\tilde{D} / D_{\text {Cr }}^{*}$ ratio increases when the temperature decreases, and tends toward 1 when $x_{\mathrm{Cr}}$ approaches zero. As an example, it ranges between 1 and 2.6 at $500{ }^{\circ} \mathrm{C}$. The quantity determined from the ${ }^{54} \mathrm{Cr}$ intensity profiles therefore overestimates the true tracer coefficient - quantifying the error would require more information about the SIMS response in the non-dilute regime.

\section{References}

[1] N. Saunders and A. P. Miodownik, CALPHAD (Calculation of Phase Diagrams): A Comprehensive Guide. Elsevier (1998).

[2] H. Lukas, S. Fries and B. Sundman, Computational Thermodynamics: The Calphad Method. Cambridge University Press (2007).

[3] A. Borgenstam, L. Höglund, J. Ågren and A. Engström, DICTRA, a tool for simulation of diffusional transformations in alloys, Journal of Phase Equilibria 21 (2000) pp. 269-280. doi: 10.1361/105497100770340057.

[4] B. Sundman, U. R. Kattner, C. Sigli, M. Stratmann, R. L. Tellier, M. Palumbo and S. G. Fries, The OpenCalphad thermodynamic software interface, Computational Materials Science 125 (2016) pp. 188-196. doi: 10.1016/j.commatsci.2016.08.045.

[5] R. Pillai, W. G. Sloof, A. Chyrkin, L. Singheiser and W. J. Quadakkers, A new computational approach for modelling the microstructural evolution and residual lifetime assessment of MCrAlY coatings, Materials at High Temperatures 32 (2015) pp. 57-67. doi: 10.1179/0960340914Z.00000000063. 
[6] O. Senninger, E. Martínez, F. Soisson, M. Nastar and Y. Bréchet, Atomistic simulations of the decomposition kinetics in $\mathrm{Fe}-\mathrm{Cr}$ alloys: Influence of magnetism, Acta Materialia 73 (2014) pp. 97 - $106 . \quad$ doi: https://doi.org/10.1016/j.actamat.2014.03.019.

[7] V. Barbe and M. Nastar, A self-consistent mean field model for concentrationdependent phenomenological coefficients: application to $\mathrm{Fe}-\mathrm{Ni}-\mathrm{Cr}$ solid solution, TMS letters 2 (2005) pp. 93-94.

[8] N. S. Kulkarni, R. J. Bruce Warmack, B. Radhakrishnan, J. L. Hunter, Y. Sohn, K. R. Coffey, G. E. Murch and I. V. Belova, Overview of SIMS-based experimental studies of tracer diffusion in solids and application to $\mathrm{Mg}$ selfdiffusion, Journal of Phase Equilibria and Diffusion 35 (2014) pp. 762-778. doi: 10.1007/s11669-014-0344-4.

[9] B. Jönsson, Assessment of the mobilities of $\mathrm{Cr}, \mathrm{Fe}$ and $\mathrm{Ni}$ in binary fcc $\mathrm{Cr}-\mathrm{Fe}$ and Cr-Ni alloys, Scandinavian Journal of Metallurgy 24 (1995) pp. 21-27.

[10] P. Gruzin and G. Fedorov, The diffusion of chromium in the nickel base solid solutions, Doklady Akademii Nauk SSSR 105 (1955) pp. 264-267.

[11] K. Monma, H. Suto and H. Oikawa, Diffusion of $63 \mathrm{Ni}$ and $51 \mathrm{Cr}$ in nickelchromium alloys, Journal of the Japanese Institute for Metals 28 (1964) pp. 188192. doi: $10.2320 /$ jinstmet1952.28.4_188.

[12] S. P. Murarka, M. S. Anand and R. P. Agarwala, Diffusion of chromium in nickel, Journal of Applied Physics 35 (1964) pp. 1339-1341. doi: 10.1063/1.1713615.

[13] J. Růžičková and B. Million, Self-diffusion of the components in the f.c.c. phase of binary solid solutions of the $\mathrm{Fe}-\mathrm{Ni}-\mathrm{Cr}$ system, Materials Science and Engineering 50 (1981) pp. 59-64. doi: 10.1016/0025-5416(81)90086-0.

[14] S. B. Jung, T. Yamane, Y. Minamino, K. Hirao, H. Araki and S. Saji, Interdiffusion and its size effect in nickel solid solutions of $\mathrm{Ni}-\mathrm{Co}, \mathrm{Ni}-\mathrm{Cr}$ and $\mathrm{Ni}-\mathrm{Ti}$ systems, Journal of Materials Science Letters 11 (1992) pp. 1333-1337. doi: 10.1007/BF00729354.

[15] B. Chetroiu, Corrosion sous contrainte de l'alliage 600 en millieu primaire des REP: étude de la diffusion du chrome. PhD thesis École Nationale Supérieure des Mines de Paris (2015). https://pastel.archives-ouvertes . fr/tel-01157822.

[16] C. Campbell and A. Rukhin, Evaluation of self-diffusion data using weighted means statistics, Acta Materialia 59 (2011) pp. 5194-5201. doi: 10.1016/j.actamat.2011.04.055.

[17] G. Fedorov, E. Smirnov and F. Zhomov, Diffusion and thermodynamic properties of nickel-chromium alloys, Metallurgiya i Metallovedenie Chistykh Metallov 4 (1963) pp. 110-121.

[18] J. Askill, Tracer diffusion in the chromium-nickel system, physica status solidi (a) 8 (1971) pp. 587-596. doi: 10.1002/pssa.2210080230.

[19] P. Moulin, A. Huntz and P. Lacombe, Influence du carbone sur la diffusion $\mathrm{du}$ chrome et du nickel en volume et dans les joints de grains de l'alliage $\mathrm{Ni}-$ Cr 80/20, Acta Metallurgica 27 (1979) pp. 1431-1443. doi: 10.1016/00016160(79)90165-2. 
[20] S. Rothman, The measurement of tracer diffusion coefficients in solids, in Diffusion in Crystalline Solids (G. Murch and A. Nowick, eds.) pp. 1-61 Academic Press (1984).

[21] S. Hofmann, Sputter depth profile analysis of interfaces, Reports on Progress in Physics 61 (1998) pp. 827-888. doi: 10.1088/0034-4885/61/7/002.

[22] J. Philibert, Atom movements - Diffusion and mass transport in solids. Les Editions de Physique, Les Ulis (1991).

[23] https://docs.scipy.org/doc/scipy/reference/odr.html.

[24] J. Tucker, R. Najafabadi, T. Allen and D. Morgan, Ab initio-based diffusion theory and tracer diffusion in $\mathrm{Ni}-\mathrm{Cr}$ and $\mathrm{Ni}-\mathrm{Fe}$ alloys, Journal of Nuclear Materials 405 (2010) pp. 216-234. doi: j.jnucmat.2010.08.003.

[25] S. J. Rothman, L. J. Nowicki and G. E. Murch, Self-diffusion in austenitic FeCr-Ni alloys, Journal of Physics F: Metal Physics 10 (1980) pp. 383-398. doi: 10.1088/0305-4608/10/3/009.

[26] B. Million, J. Růžičková and J. Vřeštál, Diffusion in $\mathrm{Fe}-\mathrm{Ni}-\mathrm{Cr}$ alloys with an f.c.c. lattice, Materials Science and Engineering 72 (1985) pp. 85-100. doi: 10.1016/0025-5416(85)90069-2.

[27] D. Pruthi, M. Anand and R. Agarwala, Diffusion of chromium in Inconel600, Journal of Nuclear Materials 64 (1977) pp. 206-210. doi: 10.1016/00223115(77)90026-5.

[28] P. Guiraldenq and P. Poyet, Étude comparative de la diffusion intergranulaire et de la désorption ultérieure du chrome vers la surface dans les alliages Ni75Cr16Fe9 (type Inconel 600) en présence de vapeur d'eau par l'emploi du radiotraceur $51 \mathrm{Cr}$, Mémoires et Études Scientifiques de la Revue de Métallurgie 77 (1980) pp. 939-949.

[29] T.-F. Chen, G. P. Tiwari, Y. Iijima and K. Yamauchi, Volume and grain boundary diffusion of chromium in Ni-base $\mathrm{Ni}-\mathrm{Cr}-\mathrm{Fe}$ alloys, Materials Transactions 44 (2003) pp. 40-46. doi: 10.2320/matertrans.44.40.

[30] J. R. Manning and L. Bruner, Diffusion kinetics for atoms in crystals, American Journal of Physics 36 (1968) pp. 922-923.

[31] B.-J. Lee, On the stability of Cr carbides, Calphad 16 (1992) pp. 121-149. doi: 10.1016/0364-5916(92)90002-F. 